\title{
Research on the Mechanism of the Role of Innovation-Influencing Factors on the Performance of Construction Projects
}

\author{
Shiming Wang and Caiyun Li $\mathbb{D}$ \\ School of Business Administration, Liaoning Technical University, Huludao 125105, China \\ Correspondence should be addressed to Caiyun Li; lgdlicaiyun@qq.com
}

Received 16 October 2021; Revised 25 December 2021; Accepted 1 February 2022; Published 27 February 2022

Academic Editor: Yingbin Feng

Copyright (C) 2022 Shiming Wang and Caiyun Li. This is an open access article distributed under the Creative Commons Attribution License, which permits unrestricted use, distribution, and reproduction in any medium, provided the original work is properly cited.

\begin{abstract}
At present, innovation has gradually become an inevitable trend of the digital transformation and competitive advantage of enterprises in the construction industry. In this paper, the structural equation model is constructed from four aspects of innovation-influencing factors, such as hindering, driving, enabling, and investing, as well as project and enterprise performance. The participants of engineering construction projects from several regions in China have been investigated. Factor analysis and structural equation model analysis have been carried out on the collected data using SPSS and AMOS software. Both drive factors and enabling factorss can play an important role in promoting innovation input. As an intermediary variable, innovation input can directly stimulate project and enterprise performance, and the improvement of enterprise performance is also positively dependent on project performance.
\end{abstract}

\section{Introduction}

As an important industry of China's national economy, the construction industry has not only made an increasingly prominent contribution to the national economy but also played an important role in promoting employment, industrial linkage, and other aspects. According to the data released by the National Bureau of Statistics, the total output value of the national construction industry in 2020 was $26,394.7$ billion yuan [1], accounting for $25.98 \%$ of the GDP. The construction industry played an important role in China's national economy. After China's economic development reached a new level, it gradually shifted from factordriven and investment-driven to innovation-driven. To adapt to the new normal, China's construction industry needs certain measures in management and technological innovation. The development direction of the modern construction industry is information-based industrial management, construction assembly, factory production, and design standardization. Therefore, as a construction enterprise, it is necessary to comprehensively promote the management innovation system according to the characteristics of the construction industry, which requires starting from the management of the enterprise, gradually changing the disjointed situation of construction links, realizing mutual penetration between construction links and design as much as possible, and improving the technical level and overall benefit of engineering construction. For the construction industry, increasing scientific and technological innovation is not only the inherent demand of realizing the modernization of the construction industry but also the strategic choice of consolidating the position of the pillar industry and enhancing the "gold content" of the "Made in China" brand. The rapid development of the construction industry has also improved the innovation level of the construction industry. The most remarkable change is that an increasing number of innovative technologies have been applied to the construction industry, which has a great impact on traditional construction technologies. It solved many technical problems that cannot be realized in traditional processes and improved the work efficiency of construction projects to a certain extent. It can be seen that innovation is a new requirement for the development of the construction industry. However, because of the technical 
complexity of construction projects and the urgent need for innovation, innovation needs a certain period, regardless of the $R \& D$ process or safety certification process [2]. At present, the innovation level of construction projects in China's construction industry is low, and the independent innovation ability of Chinese construction enterprises is weak, lagging behind that of developed countries. The R\&D of construction enterprises pays more attention to reducing costs and improving construction progress, while the awareness and ability of technological innovation are relatively weak. Moreover, because the fixity of building products determines the mobility of building production and the discreteness of production areas, there is usually a lack of adequate and stable information exchange between enterprises and between general contractors and subcontractors, which makes each department in the construction industry chain to bear its own innovation risks and costs. It greatly limits the innovation of the whole industry. At the same time, the vast majority of construction enterprises are unable to promote technology reserves and forward-looking innovation research. The ability to invest in science and technology will inevitably weaken with a decrease in the profit level even for large contractors who are capable of long-term organized and planned technology development reserves. Therefore, clarifying the essence of construction project innovation and grasping the mechanism of the influencing factors of construction project innovation on performance are the basis of solving existing problems and improving innovation efficiency and sustainable innovation ability of construction projects. In this study, the participants of Chinese construction projects are taken as the research objects. By building a structural equation model and using survey data, empirical analysis is performed to clarify the mechanism of influencing factors of construction project innovation on performance to provide a certain basis for promoting the innovative development of construction projects and deeply integrating innovation with the construction industry. Thus, it can better comply with the implementation of China's innovation-driven development strategy.

\section{Research Assumptions and Conceptual Models}

2.1. Research Assumptions. Innovation performance represents the innovation ability of construction projects[3]. The higher the innovation performance, the stronger the innovation ability. To study the mechanism of the influencing factors of the construction project innovation on performance, it is necessary to clarify the main factors of innovation and the performance level of innovation performance.

Firstly, we hypothesize the influencing factors of construction project innovation. Construction project innovation is based on complex construction projects, and its success is influenced by many factors, such as technology, manpower, management, economy, and society [4]. At present, foreign scholars have relatively mature research on the influencing factors of construction project innovation.
For example, Dikmen et al. studied the influencing factors of construction enterprise innovation system operation from several aspects, such as objectives, strategies, environmental obstacles, driving factors, and organizational investment factors [5]. Arranz et al. believed that innovation-driven and innovation-hindered influences on the ecological innovation ability of enterprises were more important [6]. The research of Ozorhon was more systematic and comprehensive and held that innovation drive, innovation input, innovation empowerment, and innovation obstacle were important factors to measure the innovation performance of construction [7]. In domestic research, Rui and Shengquan studied the influence of internal and external innovation drivers on the innovation ability of small- and medium-sized enterprises [8]. Zhang proposed four factors that affected the innovation performance of construction projects, namely the environment, resources, organization, and management [9]. China scholars' research results mostly focused on a single factor variable, and the factor classification lacks systematicness. Based on previous research results and the development status of China's construction project innovation, this paper holds that obstruction, drive, empowerment, and investment are the key factors affecting construction project innovation research.

Secondly, we hypothesize the innovation performance of construction projects. Innovation performance can have different performance types and levels. Ozorhon [7] found that innovation has improved the project in terms of cost, time, quality, and safety and has a positive impact on project performance and enterprise performance. Ghaben and Jaaron thought that innovative practice not only brought many project-level benefits, such as reducing the construction period and cost, improving quality, and improving environmental performance, but also had broader enterprise-level benefits, such as improving corporate image, customer and end-user satisfaction, and improving future business cooperation opportunities [10]. Unfortunately, there have been few empirical studies on the innovation performance of construction projects in China, and most of them have focused on the innovation performance of enterprise management. For example, Zhou and Tang found that supply chain synergy positively affected product innovation and process innovation [11]. Supply chain coordination and product innovation have positive effects on enterprise performance, and product performance can have a positive impact on enterprise performance. On the whole, China and foreign scholars' research on the innovation performance of construction projects has mainly focused on the project level and enterprise level. It should be pointed out that a construction project is a capital construction project implemented in strict accordance with capital construction procedures, while the construction enterprise refers to the investment subject or investor of the construction project, and the scope of the enterprise is larger than the scope of the project. An enterprise can contain multiple construction projects. Hence, project-level performance may have a positive impact on enterprise-level performance.

The influencing factors and performance of construction project innovation are clarified. How can the mechanism of 
action of different construction project factors on construction project innovation performance be determined? Academia generally believed that innovation performance was generally measured by input and output [12]. Inferring from this, input can be understood as an independent variable, i.e., an innovation influencing factor, and output can be understood as a dependent variable, i.e., innovation performance. As mentioned above, input itself exists as an innovation factor. In view of the scientificity and accuracy of the expression and research, this study uses the innovation input factor as a mediating variable for the other three influencing factors and mainly studies the mechanism by which the three factors, namely obstacle, drive, and empowerment indirectly influence innovation performance (project performance and enterprise performance) through the innovation input factor. Therefore, considering the actual situation, this study puts forward the following assumptions:

(H1) Innovation obstacles have a negative impact on innovation input factors.

(H2) Driving innovation factors have a positive impact on innovation input factors.

(H3) Innovation empowerment factors have a positive impact on innovation input factors.

(H4) Innovation input has a positive impact on project-level performance.

(H5) Innovation input has a positive impact on enterprise performance.

(H6) Project-level performance has a positive impact on enterprise-level performance.

(H7a) Innovation input plays an intermediary role between innovation obstacles and enterprise-level performance.

(H7b) Innovation input plays an intermediary role between driving innovation factors and enterpriselevel performance.

(H7c) Innovation input plays an intermediary role between innovation empowerment factors and enterprise-level performance.

2.2. Conceptual Models. Based on the above six assumptions, a latent variable model of the mechanism of the influencing factors of construction project innovation on performance under the background of an innovation-driven development strategy is constructed, as shown in Figure 1.

In this conceptual model, innovation obstacles include challenges that may hinder innovation. Innovation drive represents the main motive to start the innovation process. Innovation empowerment is considered a factor to overcome innovation challenges. These three influencing factors on the innovation of construction projects have jointly affected innovation input. Innovation input represents various resources for realizing innovation, which may produce corresponding results. These results are divided into projectlevel benefits and enterprise-level benefits. Project-level

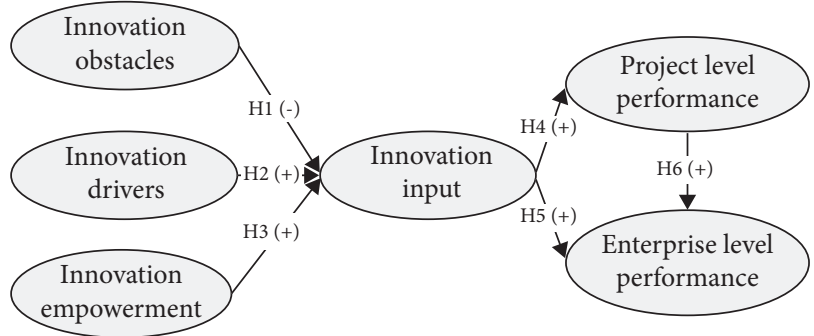

Figure 1: Conceptual model of how innovation influences performance.

benefits are innovative outputs related to project performance, while enterprise-level benefits are longer-term and wider outputs.

\section{Measurement Index Selection and Model Construction}

3.1. Selection of Measurement Index. The selection of measurement indicators in the list of factors affecting innovation of initial construction projects is mainly based on literature research. Upon reading and summarizing the relevant literature, it is found that the biggest obstacle to the innovation of construction projects is the unavailability of capital and funds needed for innovation [7], and cost, quality, and schedule management are the basic elements that need to be considered in the project. Therefore, this paper takes the basic elements as the breakthrough point and measures the obstacles to innovation using four indicators: lack of effective management, limited budget, lack of necessary building materials/tools/equipment, and lack of experienced and qualified staff. According to the related research on the driving factors of diversified innovation [12-15], this paper uses four measurement indicators: "competition, response to customer/user needs, rapid development of technology, and environment and sustainability" to measure the driving factors of construction project innovation. Based on the related literature $[16,17]$ on the influencing factors of innovation and empowerment and considering Herzberg's two-factor theory, this paper studies the innovation and empowerment factors of construction projects using four measurement indicators: "incentive, top management support, training and development, and knowledge management." Adequate resources and capacity investment are important factors affecting the success of construction projects. Combined with literature research [18] and specific conditions, this paper mainly measures the factors of innovation input in construction projects from four aspects: "material capital, technology research and development, knowledge resources, and innovation team." By integrating and summarizing scholars' research on innovative project performance and innovative enterprise performance [19-21], this paper mainly measures and studies the innovation performance at the project level from four aspects: "shortening project duration, reducing project cost, increasing productivity, and improving customer satisfaction." The innovation performance at the enterprise level is studied 
from four aspects: "gaining experience, improving technical and management capabilities, intellectual property rights, and future business cooperation."

However, the existing literature comes from different times, perspectives, and scenarios, which may have certain limitations in time and space. Therefore, semistructured interviews were conducted with designers, contractors, project managers, and other management personnel representing various institutions in the construction project industry, and the initial list of influencing factors was revised and improved. Finally, to further improve the content validity of the survey, this study takes three scholars with rich backgrounds in construction project management innovation as the objects of the pretest. They were asked to check the consistency between the revised list of factors, existing literature research, and the feasibility of actual concepts, and the feedback received was positive. Therefore, the list of influencing factors of construction project innovation is finally formed, as shown in Table 1.

3.2. Model Construction. According to the above-identified potential variables and corresponding observation variables, combined with the theoretical hypotheses put forward in the previous article, a structural equation model of the mechanism of construction project innovation influencing factors on performance is constructed, as shown in Figure 2.

\section{An Empirical Analysis of the Innovation Performance of Construction Projects}

4.1. Design and Distribution of Questionnaires. In this paper, data were collected by a questionnaire survey. Based on the list of the influencing factors of construction project innovation in Table 1, the questionnaire was designed. The questionnaire is mainly composed of two parts. The first part is to investigate the basic situation of the respondents, mainly including personal information and related investigations of the recently completed projects. The second part includes the investigation of four factors, obstruction, drive, empowerment, and investment in construction project innovation, as well as innovation performance at the project and enterprise levels. A fivelevel Likert scale is adopted, and the influence degree from low to high corresponds to $1 \sim 5$ points.

In this paper, the participants of engineering construction projects in Beijing, Shanghai, Guangdong, Liaoning, and other domestic regions are selected as research objects, including grassroots technical operators and middle-level and senior management personnel, and a random sampling survey based on project innovation is conducted by Wenjuanxing to design a network questionnaire. A total of 216 questionnaires were sent out, of which 207 were valid, with an effective recovery rate of $95.8 \%$. The purpose of this survey is to obtain essential information on the innovation value chain of construction projects. Respondents were asked to choose these factors according to their own work experience and knowledge and provide data support for studying the impact of innovation factors on the performance of construction projects.

\subsection{Descriptive Analysis of Samples}

4.2.1. Analysis of Sample Characteristics. A survey on the basic situation of the project participants shows that $61.8 \%$ of the project participants are male, and $38.2 \%$ are female. Most of the respondents $(69.1 \%)$ have worked in construction engineering-related industries for less than 5 years, and only $1.9 \%$ have worked for more than 20 years, indicating that the participants in construction projects have short working years and lack of work experience. It shows that there is a serious structural fault in the construction industry at present. Some project managers are facing retirement, while others in the project department are mostly young people who have just left school, with huge responsibilities, and the whole construction industry has a very strong desire for talents. Some enterprises pay high salaries to hire outstanding construction talent for development, resulting in personnel turnover. In addition, enterprises pay less attention to employees, which leads to the employees' lack of corporate sense of belonging and greater personnel turnover, which ultimately makes the working years of construction workers shorter. From the perspective of educational background, $82.6 \%$ of the participants had a bachelor's degree, and $9.7 \%$ had a master's degree and no doctoral degree, which shows that the construction industry lacks highly educated talent and has a low level of knowledge. In addition, from the job point of view, most of the interviewees were professional technicians $(3.4 \%$ were project directors/consultants, $23.7 \%$ were engineers, and $41.5 \%$ were professionals), and management accounted for $15.9 \%$, which showed that the technical backbone was the main contributor to the innovation of construction projects.

The basic situation of the units where the project participants work is investigated. Among them, construction-oriented construction project units account for the majority (58.9\%), and only $1 \%$ of the units mainly function as surveys and designs, which shows that construction units play an important role in the innovation of construction projects. From the nature of the units where the participants work, more than half $(55.1 \%)$ of the respondents work in state-owned enterprises (including state-owned joint-stock companies), while $31.9 \%$ of the respondents work in private enterprises (including private joint-stock companies). The proportion of personnel in foreign-funded/joint-venture enterprises and other units is low. State-owned enterprises can actively respond to policy incentives for the transformation and upgrading of the construction industry and strongly promote the innovation and development of construction projects.

\subsubsection{Basic Information on Innovation of Recently Completed} Projects. A survey of the projects recently completed by the project participants shows that more than half (57\%) of the units have recently completed projects with a total investment of more than 100 million yuan, and as shown in Figure 3, most of the projects of the construction units belong to residential quarters and infrastructure. When 
TABLE 1: List of influencing factors of construction project innovation.

\section{Potential variable}

Innovation obstacles $\left(\alpha_{1}\right)$

Innovation drivers $\left(\alpha_{2}\right)$

Innovative empowerment factors $\left(\alpha_{3}\right)$

Innovation input factors $(\beta)$

Project level performance $\left(\gamma_{1}\right)$

Enterprise level performance $\left(\gamma_{2}\right)$

\section{Observed variable \\ ZA1Lack of effective management \\ ZA2Limited budget}

ZA3Lack of necessary building materials/tools/equipment ZA4Lack of experienced and qualified staff

$$
\text { QD1Competition }
$$

QD2Respond to customer/user needs QD3The rapid development of technology

QD4Environment and sustainability

\section{FN1Encourage}

FN2Top management support

FN3Training and development

FN4Knowledge management

\section{TR1Physical capital}

TR2Technology research and development

TR3Knowledge resources

TR4Innovation team

\section{$X M 1$ Shorten the project duration}

$X M 2$ Project cost reduction

$X M 3$ Productivity increase

XM4Improved customer satisfaction

QY1Gain experience

QY2Improve technical and management capabilities

QY3Intellectual property

QY4Future business cooperation

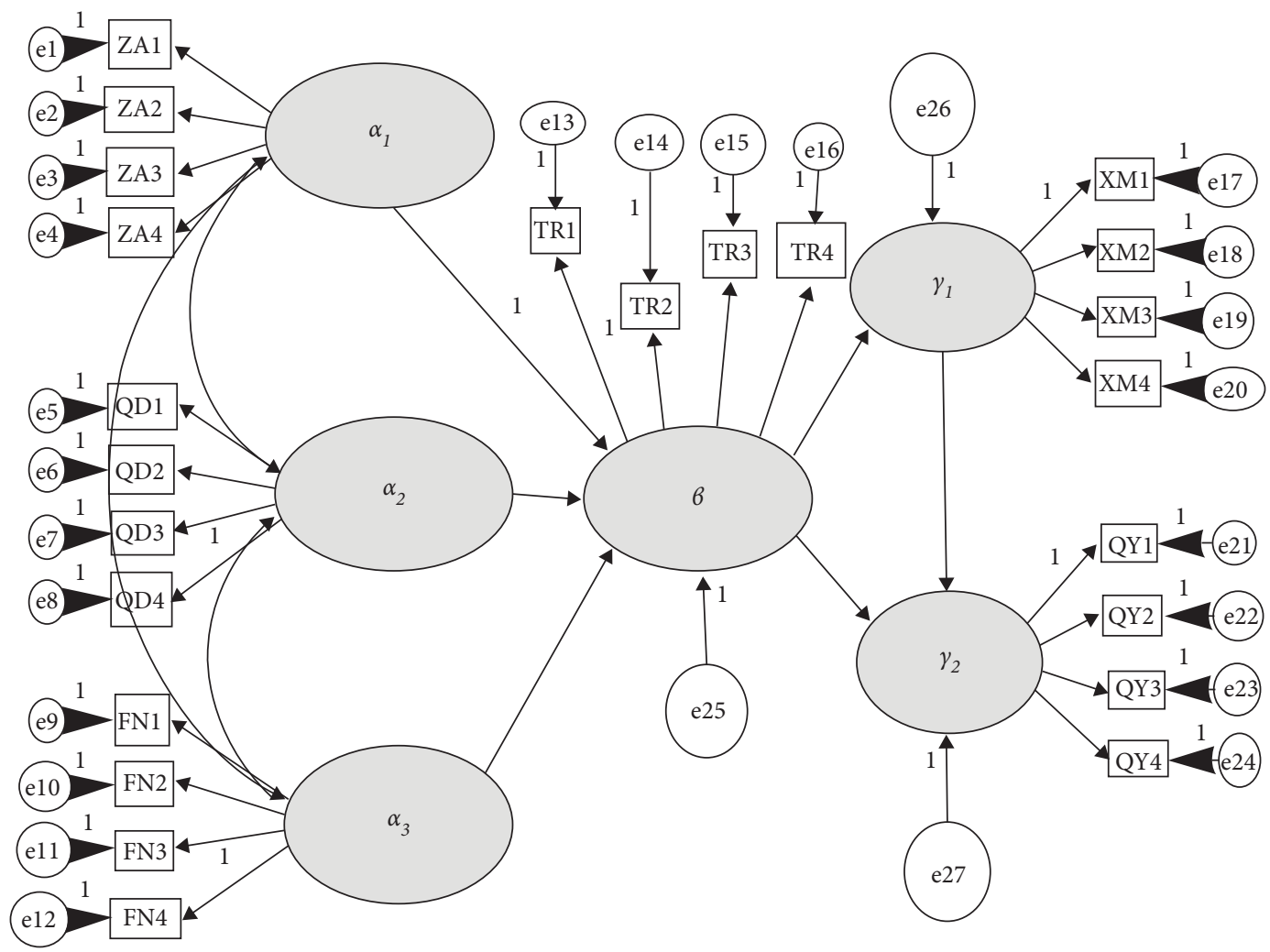

FIGURE 2: Structural equation model of the mechanism of influencing factors on performance. 


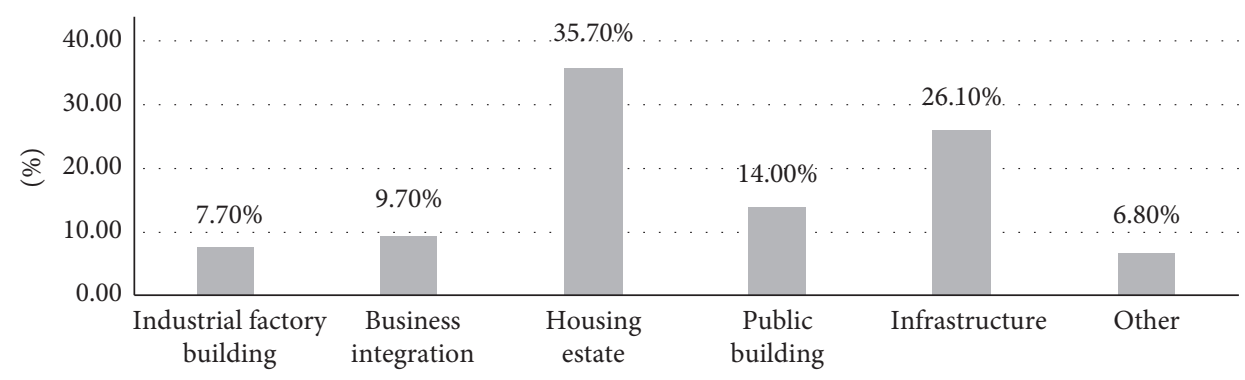

Figure 3: Project category.

investigating the actual priority of quality, construction period, and cost control of recently completed projects, it is found that most units now take quality control as the primary goal, which subverts the traditional construction industry with cost control as the premise.

Promoting comprehensive innovation with scientific and technological innovation as the core is an important part of the innovation-driven development strategy. To preliminarily understand the basic situation of current construction project innovation, this study takes the project participants' recent completion as the background for investigation. The survey results show that most $(54.1 \%)$ project participants believe that there is no innovation in recently completed projects. The innovative projects are further investigated from the perspective of innovation, and the results are shown in Figure 4. It can be seen from the figure that innovation in modern construction methods accounts for the most, whereas innovation in building information model (BIM) accounts for $19 \%$, and innovation in strategic partnership and whole process engineering consulting accounts for $10 \%$. However, innovation in supply chain cooperation, energy efficiency and sustainability, advanced materials, lean construction, automation, and marketing is less than $10 \%$. The overall innovation degree of the construction industry is low. The proportion of technological innovation is the highest, and the innovation angle is relatively concentrated. It is still necessary to continuously start and deepen innovation work to gradually realize the diversified innovation of construction projects. The interviewees had management and ownership positions and had certain work experience. They may provide reliable information about the units and the projects they participate in, which makes this research to be supported by a reliable database.

\section{Reliability and Validity Test}

5.1. Reliability Test. In this paper, the reliability of the collected questionnaire data was tested by the Cronbach reliability coefficient method of IBM SPSS Statistical 21, and the results are shown in Table 2.

As seen from Table 2, the reliability coefficients of the six subscales are as follows: the reliability of construction project innovation drivers is 0.844 , the reliability of innovation enabling factors is 0.822 , the reliability of innovation hindering factors is 0.720 , the reliability of innovation input factors is 0.878 , the reliability of project-level performance is 0.746 , and the reliability of enterprise-level performance is 0.905 , all of which are greater than 0.7 . It shows that the scale has good reliability in measuring the 24 variables that affect the innovation of construction projects, and Cronbach's alpha of the total table is 0.923 , which is greater than 0.8 . It shows that the scale design and sample data quality have good reliability.

5.2. Validity Test. In this study, exploratory factor analysis and confirmatory factor analysis were used to test the validity, and the test results are shown in Table 3.

The exploratory factor analysis of the sample data by IBM SPSS Statistical 21 shows that the significance level of Bartlett's test is sig. $=0.00<0.05$, and the KMO measure value of the sample is 0.849 , which indicates that the sample data are suitable for factor analysis.

A confirmatory factor analysis was carried out on the data by AMOS. From the results in Table 3, it can be seen that the standard factor load of all observed variables is greater than 0.5 , and the AVE value of potential variables is greater than 0.5 , which indicates that each observed variable can effectively reflect its corresponding potential variables. The overall validity test results show that the scale has high validity.

In summary, the sample data obtained by the questionnaire survey not only have high consistency but can also objectively and truly reflect the corresponding potential variables, which meets the basic requirements of structural equation model analysis.

\section{Model Operation Results and Discussion}

6.1. Master Model Test. On the basis of testing the reliability and validity of the structural equation model, this study uses AMOS 24.0 to process and calculate the structural equation model and obtains the index values of the model fitting degree test, as shown in Table 4 . The chi-square ratio of freedom (CMIN/DF) is the minimum sample difference divided by the degree of freedom. If its value is less than 4 , it shows that the model has a good fitting degree. The mean square root of the progressive residual (RMSEA) is used to measure the difference between the theoretical model and the fully fitted model, which is usually regarded as the most important adaptation index information. Generally, if the value is less than 0.05 , the model fits very well. The fitness 


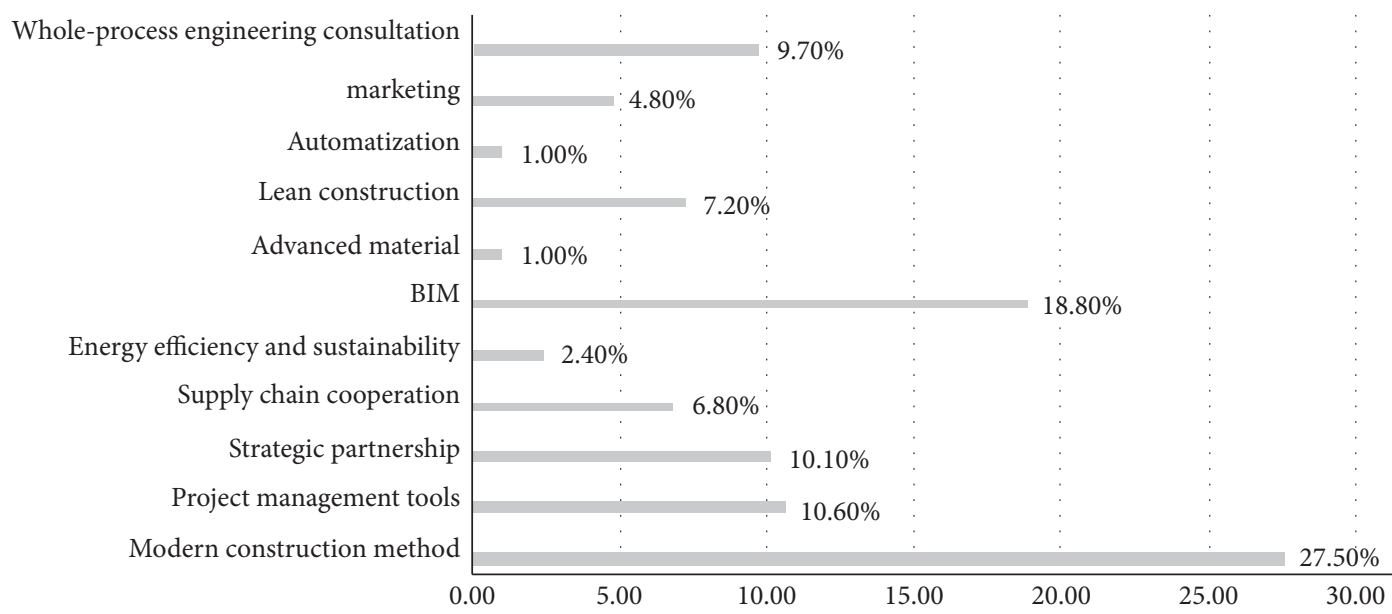

(\%)

Figure 4: Innovation perspective.

TABle 2: Cronbach's alpha coefficient.

\begin{tabular}{lcc}
\hline Study variables & Cronbach's alpha & Number of terms \\
\hline$\alpha_{1}$ & 0.844 & 4 \\
$\alpha_{2}$ & 0.822 & 4 \\
$\alpha_{3}$ & 0.720 & 4 \\
$\beta$ & 0.878 & 4 \\
$\gamma_{1}$ & 0.746 & 4 \\
$\gamma_{2}$ & 0.905 & 4 \\
Total & 0.923 & 24 \\
\hline
\end{tabular}

TABLE 3: Test results of the model.

\begin{tabular}{|c|c|c|c|}
\hline Potential variable & Observed variable & Factor loading & AVE \\
\hline \multirow{4}{*}{$\alpha_{1}$} & $Z A 1$ & 0.65 & \multirow{4}{*}{0.57} \\
\hline & $Z A 2$ & 0.61 & \\
\hline & $Z A 3$ & 0.60 & \\
\hline & $Z A 4$ & 0.66 & \\
\hline \multirow{4}{*}{$\alpha_{2}$} & QD1 & 0.71 & \multirow{4}{*}{0.65} \\
\hline & QD2 & 0.58 & \\
\hline & QD3 & 0.86 & \\
\hline & QD4 & 0.87 & \\
\hline \multirow{4}{*}{$\alpha_{3}$} & FN1 & 0.59 & \multirow{4}{*}{0.55} \\
\hline & FN2 & 0.64 & \\
\hline & FN3 & 0.86 & \\
\hline & FN4 & 0.84 & \\
\hline \multirow{4}{*}{$\beta$} & TR1 & 0.74 & \multirow{4}{*}{0.63} \\
\hline & TR2 & 0.83 & \\
\hline & TR3 & 0.83 & \\
\hline & TR4 & 0.78 & \\
\hline \multirow{4}{*}{$\gamma_{1}$} & $X M 1$ & 0.56 & \multirow{4}{*}{0.58} \\
\hline & $X M 2$ & 0.60 & \\
\hline & $X M 3$ & 0.75 & \\
\hline & $X M 4$ & 0.70 & \\
\hline \multirow{4}{*}{$\gamma_{2}$} & QY1 & 0.77 & \multirow{4}{*}{0.70} \\
\hline & QY2 & 0.86 & \\
\hline & QY3 & 0.83 & \\
\hline & QY4 & 0.88 & \\
\hline
\end{tabular}

TABLE 4: Structural equation model fitting degree test.

\begin{tabular}{cccccc}
\hline Fitting index & CMIN/DF & $P$ & RMSEA & GFI & AGFI \\
\hline Fitting result & 2.624 & $P \leq 0.001$ & 0.046 & 0.911 & 0.905 \\
\hline
\end{tabular}

index (GFI) is the explanatory degree of variance and covariance of observed sample data, and its value is greater than 0.9 , which indicates that the model path map has a good fitness with the actual data. AGFI is the adjusted fitness index, and it is generally considered that AGFI is greater than 0.9 , which means that the fitness of the assumed model is good.

It can be seen from the fitting degree test results in Table 4 that the ratio of the chi-square degrees of freedom is between 1 and 3, indicating that the model has a simple degree of adaptation, and the RMSEA value is 0.046 , indicating that the model is well-adapted, with GFI and AGFI values greater than 0.9 . On the whole, the hypothesis of the structural equation model of the action mechanism fits well with the sample data.

In the structural equation model, when the factor load (path coefficient) between the latent variable and the observed variable is between 0.5 and 0.95 , it can be considered that the model has good adaptability. According to the test results of the causal model of the action mechanism in Table 5, all path coefficients are basically at a significant level, and the assumptions of the action mechanism model of construction project innovation influencing factors on performance have been verified, which shows that the model constructed in this study is reasonable.

The obstacles to innovation mainly consist of four firstorder variables: lack of effective management, limited budget, lack of necessary building materials/tools/equipment, and lack of experienced and qualified staff. The factor loads of these four observed variables on innovation obstacles are $0.65,0.61,0.60$, and 0.66 , respectively, which reach a significant positive correlation level, i.e., they have strong explanatory power on innovation obstacles. The path 
TABLE 5: Test results of hypothesis.

\begin{tabular}{lcccc}
\hline Model path & Correspondence hypothesis & Standardized path coefficient & $P$ & Test result \\
\hline$\alpha_{1} \longrightarrow \beta$ & Innovation barriers $\longrightarrow$ innovation inputs & -0.47 & $P \leq 0.001$ Hypothesis 1 holds \\
$\alpha_{2} \longrightarrow \beta$ & Innovation-driven $\longrightarrow$ innovation input & 0.64 & $P \leq 0.001$ Hypothesis 2 holds \\
$\alpha_{3} \longrightarrow \beta$ & Innovation empowerment $\longrightarrow$ innovation investment & 0.55 & $P \leq 0.001$ Hypothesis 3 holds \\
$\beta \longrightarrow \gamma_{1}$ & Innovation input $\longrightarrow$ project level performance & 0.76 & $P \leq 0.001$ Hypothesis 4 holds \\
$\beta \longrightarrow \gamma_{2}$ & Innovation investment $\longrightarrow$ enterprise performance & 0.66 & $P \leq 0.001$ Hypothesis 5 holds \\
$\gamma_{1} \longrightarrow \gamma_{2}$ & Project level performance $\longrightarrow$ enterprise-level performance & 0.68 & $P \leq 0.001$ Hypothesis 6 holds \\
\hline
\end{tabular}

coefficient of innovation obstacles to innovation input factors is -0.47 . Through the significance test, it shows that innovation obstacles can have a negative impact on innovation input, and the stronger the innovation obstacles, the weaker the innovation input because the most fundamental way to hinder project innovation is to reduce the input of resources needed for the project, i.e., to have a negative impact on innovation input. At the same time, it also shows that the lack of effective management, limited budget, necessary building materials/tools/equipment, and experienced and qualified staff will directly affect the obstacles to innovation, thus affecting innovation investment and ultimately affecting innovation performance.

The driving factors of innovation are composed of four first-order variables: competition, response to customer/user needs, the rapid development of technology, and environment and sustainability. The factor loads of these four observation variables on innovation driving factors are 0.71 , $0.58,0.86$, and 0.87 , respectively, which reach a significant positive correlation level, indicating that they have good explanatory power on innovation driving factors. The path coefficient of innovation driving factors to innovation input factors is 0.64 , which is significantly positively correlated with innovation input factors, indicating that if the innovation driving is stronger, the investment in innovation is more likely to increase. Specifically, competition, responding to customer/user needs, and the rapid development of technology, the environment and sustainability will affect innovation investment, thus indirectly affecting innovation performance.

The factors of innovation empowerment are measured by four dimensions: motivation, top management support, training and development, and knowledge management. The factor loads of the four observed variables on the innovation empowerment factors are $0.59,0.64,0.86$, and 0.84 , which are significantly positively correlated, indicating that the four observed variables have strong explanatory power as innovation empowerment factors. The path coefficient of the innovation empowerment factor to the innovation input factor is 0.55 , which is positively correlated with the innovation input factor. It indicates that if innovation empowerment is stronger, innovation input is more likely to increase. Therefore, incentives, top management support, training and development, and knowledge management can have a certain degree of impact on innovation investment and ultimately indirectly affect innovation performance.

From the standardized path coefficient diagram of the structural equation model in Table 5, it can be seen that the path coefficient of innovation driving innovation input
(0.64) is greater than that of innovation empowerment driving innovation input (0.55), indicating that innovation driving has a more significant impact on innovation input. It may be because innovation drive is more specific and stronger than innovation empowerment, which can better implement innovative projects and vigorously promote the transformation of the economic development model. Moreover, in recent years, China has vigorously implemented an innovation-driven development strategy, and innovation has become a hot topic. Under this background, various industries actively strengthen investment in innovation elements and drive innovation development to improve the core competitiveness of enterprises.

Innovation input has a significant impact on both projectlevel performance and enterprise-level performance. The path coefficient (0.76) of innovation investment on project-level performance is greater than the path coefficient (0.66) of innovation investment on enterprise-level performance, indicating that innovation investment has a significant impact on project-level performance. As construction projects are the basic units for implementing innovative design schemes, the results of innovation investment can be directly expressed at the project level and enterprise level, and the innovation performance of construction projects will have a positive impact on enterprise innovation performance. The success of construction projects can have a certain degree of direct impact on enterprise performance, which also verifies the path analysis results of projectlevel performance on enterprise-level performance in Table 5.

6.2. Mediating Effect Analysis. To explore whether the innovation input in the conceptual model is an intermediary variable, the bootstrap method proposed by Hair [22-24] that is widely cited in existing studies is used to test the intermediary effect, and VAF is used to evaluate the intermediary effect. When VAF is less than $20 \%$, it shows that there is no intermediary effect, when $\mathrm{VAF}<20 \%<80 \%$, it indicates a partial mediating effect, and when VAF $>80 \%$, it indicates a complete mediation effect.

Firstly, the factors of innovation obstacles, driving, and empowerment are taken as independent variables. The innovation input is taken as a mediating variable, the enterprise-level performance is taken as a dependent variable, and the mediating effect is judged by the VAF value. The results are shown in Table 6.

The data in the table shows that the VAF value of the innovation barriers to enterprise-level performance is $88.89 \%$, which is greater than $80 \%$, indicating that 
TABLE 6: Intermediary effect of innovation input.

\begin{tabular}{lccccccc}
\hline Suppose & $\begin{array}{c}\text { Independent } \\
\text { variable }\end{array}$ & $\begin{array}{c}\text { Mediator } \\
\text { variable }\end{array}$ & $\begin{array}{c}\text { Dependent } \\
\text { variable }\end{array}$ & $\begin{array}{c}\text { Dependent } \\
\text { variable }\end{array}$ & VAF & Group effect (\%) & Intermediary effect \\
\hline H7a & ZA & TR & QY & 0.048 & 0.054 & 88.89 & $\begin{array}{c}\text { Complete } \\
\text { mediation } \\
\text { Complete } \\
\text { mediation }\end{array}$ \\
H7b & QD & TR & QY & 0.087 & 0.096 & 93.63 & $\begin{array}{c}\text { Complete } \\
\text { mediation }\end{array}$ \\
\hline
\end{tabular}

innovation input has a complete mediating effect between innovation barriers and enterprise-level performance, i.e., innovation barriers indirectly affect enterprise-level performance by influencing innovation input, which proves the above hypothesis H7a. The VAF value of innovation drivers to enterprise-level performance is $93.63 \%$, which shows that the mediating effect of innovation input between innovation drivers and enterprise-level performance is completely mediating, which proves the above hypothesis H7b. The VAF value of innovation empowerment factors on enterprise-level performance is $87.10 \%$, which also shows that the mediating effect of innovation input factors between innovation empowerment factors and enterprise-level performance is completely mediating, which proves the above hypothesis $\mathrm{H} 7 \mathrm{c}$.

\section{Conclusion and Recommendation}

Mainly based on the literature research, this paper takes the participants of domestic construction projects as the survey object, clarifies the influencing factors in the process of construction project innovation, and analyses the mechanism of the influencing factors of construction project innovation on performance using the structural equation model, which provides a reference for the development of construction project innovation. The results show that the influencing factors of construction project innovation can be divided into four categories: obstruction, driving, empowerment, and investment. These four factors, in turn, affect innovation performance at the project and enterprise levels. Among them, the innovation hindering factors can inhibit the investment of innovation elements, thus hindering the implementation and development of innovation projects. Both innovation driving factors and innovation enabling factors can have a positive impact on innovation investment, and the three factors can make concerted progress to promote the success of innovation projects. As an intermediate variable, innovation input can directly have a positive impact on project performance and corporate performance, while project performance has a positive correlation with corporate performance.

From this, it can be seen that enterprises related to construction projects can reduce the impact of innovation barriers, increase the impact of innovation drivers and empowerment and investment factors through a series of measures to improve project performance, ultimately improve enterprise performance, accelerate the transformation and upgrading of the construction industry, and conform to the innovation-driven development strategy, and it can be considered from the following aspects:

7.1. Appropriately Increase the Input of Resources Required for Engineering Innovation. Funds, personnel, machinery, and technology are the basic resources in the process of construction project innovation. The process of construction project innovation is the process of uniting, integrating, and applying various resources in a complex system. Because the staff's flexibility and subjective enthusiasm in adopting innovative ideas, technologies, and products are important driving forces for innovation and development, and the main body of engineering participants needs to acquire knowledge and experience, increase investment in technology research and development to develop appropriate information resources and tools to adopt advanced construction innovation practice. Therefore, each participant in the construction project should increase appropriate input based on the various resources required by the project, such as raising staff salaries, increasing project budgets, and other measures. At the same time, we make full use of the resource integration advantages of the engineering innovation network to form an innovation achievement information-sharing mechanism based on the completion of the innovation project and maximize the benefits of collaborative innovation.

7.2. Implement the "Assessment-Training-Assessment" System to Strictly Select Innovative Project Staff. To benefit from innovation research and absorb research results from other places, construction enterprises need to have some internal technical capabilities. To make full use of knowledge transfer required by innovation, construction enterprises must have enough "absorptive capacity." In this respect, it is particularly important for construction enterprises to employ professional, qualified staff who can explain the research results and act accordingly. Staff is the main body of innovation management in construction projects. When selecting staff in construction enterprises, first of all, the project leader should check the staff's qualification certificate and determine the employment situation of staff by examining the basic knowledge of the innovation project before joining the job. Then, the construction enterprise should train the staff to be hired through innovative education, and finally, only the staff who have passed the formal induction examination can go to work. 
7.3. Strengthen Technological Innovation. The rapid development of science and technology in the era of a knowledge economy makes all walks of life strive to strengthen innovation and lead development with innovation. The level of technological innovation has gradually become the key factor to success in market competition. Innovative engineering projects have the characteristics of a heavy workload, long-term construction process, high risk, multiple participants, complex contract terms, and multiple contents to be coordinated. Therefore, to ensure the effective and stable operation of construction project innovation, it is necessary to strengthen the technological innovation of construction projects. Moreover, researchers are paying increasing attention to digital transformation. As the foundation of information technology, such as digital computers and multimedia, digitalization is very important in terms of technology applications. Therefore, all participants in the innovation of construction projects should strengthen their technological innovation capabilities and improve their efficiency in the context of the rapid development of informatization. However, the level of technological innovation in China's construction industry is generally low. To better meet the challenges of economic globalization and implement the country's "innovationdriven development strategy," the engineering innovation team must use comprehensive engineering planning, systematic construction organization, management and coordination, complete control and implementation, meet the functions required by innovative design, and ensure the realization of the objectives of quality, budget, and safety of innovative projects. Construction enterprises should increase the number of scientific research results, ensure the quality of technological research and development, improve the rate of technological equipment, and improve the level of technological innovation and development of construction enterprises from various aspects.

7.4. The Government Should Accelerate the Promotion of Independent Innovation. The government should implement effective management of national or local political, economic, and social public affairs and assume corresponding responsibilities in accordance with relevant laws and regulations. Therefore, the government should give full play to its functions, focus on innovation-driven development strategy goals, firmly grasp the main line of construction industry transformation and upgrading, take the implementation of scientific and technological innovation as the carrier and key technology research as the starting point, strengthen basic research and new technology research, and strengthen the key links of the construction industry. To break through the bottleneck faced by industrial transformation and upgrading, strive to promote the innovation level of key nodes among the international advanced ranks, and inject a strong impetus into economic development.

Despite comprehensive consideration of the impact of multiple factors on the innovation of construction projects, this article still has shortcomings and needs to be improved. The main manifestations are as follows: the research methods of the factors affecting the innovation of construction projects are complicated, and the indicators for evaluating the key factors affecting the innovation of construction projects are also complicated. In many cases, this article only selects measurement indicators through limited literature. Although it is more realistic, it must not be comprehensive. Hence, there is room for improvement in the selection of factor measurement indicators.

\section{Data Availability}

The data that support the findings of this study are available from the corresponding author upon reasonable request.

\section{Conflicts of Interest}

The authors declare that they have no conflicts of interest.

\section{Acknowledgments}

This work was supported in part by 2021 Liaoning Provincial Social Science Planning Fund Project (Research on the Implementation Mechanism and Policy of Digital Transformation of Construction Industry in Liaoning Province Driven by Technological Innovation), China, under Grant L21BGL027.

\section{References}

[1] "The national economy will recover stably in 2020, the completion of the main goals is better than expected," Jan 2021, http://www.stats.gov.cn/tjsj/zxfb/202101/t20210118_ 1812423.html.

[2] China Construction Industry Association, Research Report on Development Strategy and Industrial Policy of China's Construction Industry (Part I), China Building Industry Press, Beijing, China, 2011.

[3] L. Gang, L. Han, and Y. Jianling, "Venture capital reputation, syndication and corporate innovation performance-empirical study based on new OTC market," China Soft Science, vol. 2018, no. 12, pp. 110-125, 2018.

[4] L. Bocong, Engineering Innovation: Breaking Barriers and Avoiding Traps, Zhejiang University Press, Hangzhou, China, 2010.

[5] I. Dikmen, M. T. Birgonul, and U. Artuk, "Integrated framework to investigate value innovations," Engineering Management, vol. 2, no. 81, pp. 81-90, 2005.

[6] N. Arranz, M. F. Arroyabe, A. Molina-García, and J. C. F. de Arroyabe, "Incentives and inhibiting factors of ecoinnovation in the Spanish firms," Journal of Cleaner Production, 2019.

[7] B. Ozorhon, "Analysis of construction innovation process at project level," Journal of Management in Engineering, vol. 29, no. 4, pp. 455-463, 2013.

[8] M. Rui and X. Shengquan, "Study on the model of influencing factors of innovation ability of small and medium-sized enterprises," Science and Technology Management Research, vol. 39, no. 06, pp. 11-16, 2019.

[9] Z. Zhang, "Research on key influencing factors and mechanism of construction engineering innovation," Central South University, Hunan, China, Dissertaion, 2014.

[10] R. K. Ghaben and A. A. M. Jaaron, "Identifying and assessing innovation factors in construction projects in Palestine: an 
empirical study," International Journal of Project Organisation and Management, vol. 9, no. 4, pp. 350-372, 2017.

[11] S. Zhou and W. Tang, "Research on the relationship among supply chain collaboration, technological innovation and enterprise performance," Statistics and Decision, vol. 16, pp. 178-181, 2015.

[12] B. Ozorhon, K. Oral, and S. Demirkesen, "Investigating the components of innovation in construction projects," Journal of Management in Engineering, vol. 32, no. 3, 2016.

[13] B. A. G. Bossink, "Managing drivers of innovation in construction networks," Journal of Construction Engineering and Management, vol. 130, no. 3, pp. 337-345, 2004.

[14] E. S. Slaughter, "Implementation of construction innovations," Building Research \& Information, vol. 28, no. 1, pp. 2-17, 2000.

[15] C. H. Nam and C. B. Tatum, "Leaders and champions for construction innovation," Construction Management \& Economics, vol. 15, no. 3, pp. 259-270, 1997.

[16] E. V. Suprun and R. A. Stewart, "Construction innovation diffusion in the Russian Federation," Construction Innovation, vol. 15, no. 3, pp. 278-312, 2015.

[17] M. Loosemore and S. Holliday, "Pro-innovation bias in construction-enablers and risks," in Proceedings of the 28th Annual ARCOM Conference, Association of Researchers in Construction Management, S. D. Smith, Ed., pp. 787-796pp. 787-, Edinburgh, UK, 2012.

[18] C. Jin, Innovation Management of Complex Product System, Science Press, Beijing, 2007.

[19] D. Eaton, R. Akbiyikli, and M. Dickinson, "An evaluation of the stimulants and impediments to innovation within PFI/ PPP projects," Construction Innovation, vol. 6, no. 2, pp. 63-67, 2006.

[20] C. B. Tatum, "Organizing to increase innovation in construction firms," Journal of Construction Engineering and Management, vol. 4, no. 602, pp. 602-617, 1989.

[21] H. L. Williams, "Intellectual property rights and innovation: evidence from the human genome," Journal of Political Economy, vol. 121, no. 1, pp. 1-27, 2013.

[22] A. Díaz, K. Rowshankish, and T. Saleh, "Why data culture matters," McKinsey Quarterly, vol. 2018, no. 3, pp. 1-17, 2018.

[23] Y. Liu, "Research on the influence of data analysis ability of employees in aerospace enterprises on individual work performance," Harbin Institute of Technology, Heilongjiang, China, Dissertaion, 2020.

[24] W. Xueyan, "Research on the influence mechanism of institution-based trust on information disclosure intention in mobile office application," Harbin Institute of Technology, Heilongjiang, China, Dissertaion, 2020. 